\title{
Analysis of the Rickettsia africae genome reveals that virulence acquisition in Rickettsia species may be explained by genome reduction
}

\author{
Pierre-Edouard Fournier ${ }^{1}$, Khalid El Karkouri ${ }^{1}$, Quentin Leroy ${ }^{1}$, \\ Catherine Robert ${ }^{1}$, Bernadette Giumelli ${ }^{1}$, Patricia Renesto ${ }^{1}$, \\ Cristina Socolovschi ${ }^{1}$, Philippe Parola ${ }^{1}$, Stéphane Audic ${ }^{2}$ and Didier Raoult*1
}

\author{
Address: ${ }^{1}$ Unité des rickettsies, IFR 48 CNRS UMR 6020, Faculté de médecine, Université de la Méditerranée, 27 Boulevard Jean Moulin, 13385 \\ Marseille cedex 05, France and 2Information Génomique et Structurale, CNRS UPR2589, Institut de Biologie structurale et Microbiologie, \\ Marseille, France \\ Email: Pierre-Edouard Fournier - Pierre-Edouard.Fournier@univmed.fr; Khalid El Karkouri - Khalid.Elkarkouri@univmed.fr; \\ Quentin Leroy - Quentin.Leroy@univmed.fr; Catherine Robert - Catherine.Robert@univmed.fr; \\ Bernadette Giumelli - Bernadette.Giumelli@univmed.fr; Patricia Renesto - prenesto@embl.fr; \\ Cristina Socolovschi - Cristina.Socolovschi@univmed.fr; Philippe Parola - Philippe.Parola@univmed.fr; \\ Stéphane Audic - Stephane.Audic@igs.cnrs-mrs.fr; Didier Raoult* - didier.raoult@gmail.com \\ * Corresponding author
}

Published: 20 April 2009

BMC Genomics 2009, 10:166 doi:10.1186/147I-2164-10-166

This article is available from: http://www.biomedcentral.com//47/-2/64//0/166

(C) 2009 Fournier et al; licensee BioMed Central Ltd.

This is an Open Access article distributed under the terms of the Creative Commons Attribution License (http://creativecommons.org/licenses/by/2.0), which permits unrestricted use, distribution, and reproduction in any medium, provided the original work is properly cited.
Received: 7 November 2008

Accepted: 20 April 2009

\begin{abstract}
Background: The Rickettsia genus includes 25 validated species, 17 of which are proven human pathogens. Among these, the pathogenicity varies greatly, from the highly virulent $R$. prowazekii, which causes epidemic typhus and kills its arthropod host, to the mild pathogen $R$. africae, the agent of African tick-bite fever, which does not affect the fitness of its tick vector.

Results: We evaluated the clonality of $R$. africae in 70 patients and 155 ticks, and determined its genome sequence, which comprises a circular chromosome of I,278,540 bp including a tra operon and an unstable 12,377-bp plasmid. To study the genetic characteristics associated with virulence, we compared this species to $R$. prowazekii, $R$. rickettsii and $R$. conorii. $R$. africae and $R$. prowazekii have, respectively, the less and most decayed genomes. Eighteen genes are present only in $R$. africae including one with a putative protease domain upregulated at $37^{\circ} \mathrm{C}$.

Conclusion: Based on these data, we speculate that a loss of regulatory genes causes an increase of virulence of rickettsial species in ticks and mammals. We also speculate that in Rickettsia species virulence is mostly associated with gene loss.
\end{abstract}

The genome sequence was deposited in GenBank under accession number [GenBank: NZ AAUYOI00000I].

\section{Background}

Rickettsiae are obligate intracellular Gram-negative bacteria mostly associated to arthropods, some of which caus- ing mild to severe diseases in humans. Pathogenic species are classified into two groups based on phylogenetic analyses [1]. The typhus group (TG) includes two Rickettsia 
prowazekii (R. prowazekii) and R. typhi, and the spotted fever group (SFG) includes 15 pathogenic species and numerous species of unknown pathogenicity $[2,3]$. Two additional validated species, $R$. bellii and $R$. canadensis, and a variety of unvalidated species from insects or leeches are organized into the most outer outgroups of the genus Rickettsia [3-5]. The relatively low rate of lateral gene transfer, the continuous gene loss and the colinearity of most of their genomes make Rickettsia species an outstanding model for comparative genomics $[4,6,7]$. Indeed, genome reduction [8] paradoxically results in higher virulence in $R$. prowazekii.

The pathogenic mechanisms of rickettsiae are unclear. Within ticks, rickettsiae remain quiescent during the starvation of their vector but undergo a reversion to the virulent state, termed reactivation, following incubation at $37^{\circ} \mathrm{C}$ or blood meal [9]. This phenomenon is marked in $R$. rickettsii by morphological changes in the microcapsular and slime layers [9]. The precise molecular mechanisms of this change, however, are only poorly understood. During human infection, attachment to and invasion of host cells were suggested to involve the outer membrane proteins rOmpA and $\mathrm{rOmpB}$ and the adhesins Adr1 and Adr2 [10,11]. A phospholipase D activity was proposed to play a role in escape from phagosomes $[8,12]$, and intracellular motility was demonstrated to rely on actin polymerization $[13,14]$. None of these factors nor the presence of a type IV secretion system [15], however, explain the virulence differences observed among Rickettsia species [6].

Over the last ten years, $R$. africae has emerged as the causative agent of African tick-bite fever [2], the most common SFG rickettsiosis both in terms of seroprevalence [16] and incidence [17-20]. Such an epidemiologic success is due to various factors, including the increase of tourism to wildlife parks in sub-Saharan Africa, the attack host-seeking behavior of its vector ticks,Amblyomma sp., and the elevated prevalence of $R$. africae in these ticks, with infection rates of up to $100 \%$ [21]. In addition, the bacterium has been identified in other areas with warm climates, such as the West Indies, where it was found in Guadeloupe, Martinique, St Kitts and Nevis, and Antigua islands [2]. Such a distribution, as well as the presence of $R$. africae in Reunion island, is likely to result from the transfer from Africa of cattle bearing infected ticks [2]. Tick-associated rickettsiae may infect ticks feeding on infected hosts or may be passed from one generation to the next transovarially. $R$. africae is transmitted transovarially and appears to be the most successful rickettsia in its adaptation to its vector tick, as the prevalence of tick infection is higher than that of any other rickettsia [22]. In addition, infection does not appear to alter tick fitness (P. Parola, unpublished data).
These data highlight the fact that $R$. africae is an extremely successful and fit bacterium.

By comparison with $R$. conorii, the second most prevalent SFG rickettsia in Africa, whose genome has previously been sequenced [23], R. africae exhibits a higher prevalence in ticks [2], a lower virulence in humans [17], and a greater genetic homogeneity [24]. The genetic factors underlying these characteristics are, however, unknown. We assumed that the $R$. africae genome sequence might help understand the characteristics of this species and the genetic mechanisms associated with the difference in virulence. Here, we present the sequence of the R. africae genome and additional data that suggest that this species has emerged recently. In support of this hypothesis, we show that $R$. africae is a clonal population. We also present data that support the assumption that rickettsial virulence increases following gene inactivation.

\section{Results}

\section{General Features of the Genome}

The genome of $R$. africae consists of two replicons: a circular chromosome of 1,278,540 base pairs (bp) (Figure 1) and a 12,377 bp circular plasmid (Table 1, Figure $2[25,26])$. We acknowledge the fact that the ESF- 5 strain, first isolated in 1966 [27], may have undergone loss or rearrangement of plasmid or chromosomal genes during multiple passages in cell culture. Sequences were deposited in GenBank under accession number [GenBank: NZ AAUY01000001]. The chromosome has a G + C content of $32.4 \%$, in the range of other SFG rickettsial genomes $(32.3-32.5 \%)$, whereas the plasmid has a G + C content of $33.4 \%$, similar to those of $R$. felis (33.2 and $33.6 \%$ ) [28] but higher than that of $R$. massiliae plasmids (31.4\%). The predicted total complement of 1,271 open reading frames (ORFs), 1,260 chromosomal $(78.26 \%$ coding sequence), and 11 plasmidic $(81.3 \%$ coding sequence) ORFs [see Additional file 1], is in the range of genomes from SFG rickettsiae with the exception of $R$. felis, which exhibits a larger genome (Table 1). Of these, $1,117(87.9 \%)$ exhibited homologs in the non-redundant database, and 1,024 (80.5\%) were assigned putative functions [see Additional file 2]. Overall, the 1,260 chromosomal ORFs encoded 1,112 protein-coding genes, with 87 of these being split into 2 to 10 ORFs by the presence of one to several stop codons. By comparison with other SFG genomes, $R$. africae had fewer split genes than any other species with the exception of $R$. felis (Table 1 ). In addition, $R$. africae exhibited a single rRNA operon, with non-contiguous $16 \mathrm{~S}$ and 23S rRNA genes as in other rickettsial genomes, 33 tRNAs and another three RNAs. The R. africae chromosome exhibited an almost perfect colinearity with the R. conorii genome [23], with the exception of a 88,459bp inversion [see Additional file 3]. At both extremities of the inversion, there were repeats of the Rickettsia palindro- 
Table I: General features of Rickettsia genomes.

\begin{tabular}{|c|c|c|c|c|c|}
\hline Species (strains) & Genome size (bp) & G+C content (\%) & Protein-coding genes & RNAs & References \\
\hline \multicolumn{6}{|l|}{ Spotted fever group } \\
\hline R. africae (ESF-5) & $1,290,917$ & 32.4 & 1,123 & 39 & Present study \\
\hline Chromosome & $\mathrm{I}, 278,540$ & 32.4 & 1,112 & 39 & \\
\hline Plasmid pRA & 12,377 & 33.4 & II & 0 & \\
\hline R. akari (Hartford) & 1,23106 & 32.3 & 1,259 & 35 & $*$ \\
\hline R. conorii (Malish 7) & $1,268,755$ & 32.4 & $\mathrm{I}, 374$ & 39 & {$[23]$} \\
\hline R. felis (URRWXCal2) & $1,587,240$ & 32.5 & 1,512 & 39 & {$[28]$} \\
\hline Chromosome & $\mathrm{I}, 485,148$ & 32.5 & $\mathrm{I}, 444$ & 39 & \\
\hline Plasmid pRF & 62,829 & 33.6 & 68 & 0 & \\
\hline Plasmid pRF $\delta$ & 39,268 & 33.2 & 44 & 0 & \\
\hline R. massiliae (Mtu5) & $1,376,184$ & 32.5 & 1,192 & 39 & [29] \\
\hline Chromosome & $1,360,898$ & 32.5 & 1,180 & 39 & \\
\hline Plasmid pRMA & 15,286 & 31.4 & 12 & 0 & \\
\hline R. rickettsii (Sheila Smith) & $1,257,710$ & 32.5 & I,345 & 36 & $*$ \\
\hline R. rickettsii (lowa) & $1,268,175$ & 32.4 & $\mathrm{I}, 384$ & 37 & {$[25]$} \\
\hline R. sibirica $(246)$ & $1,250,021$ & 32.5 & 1,083 & 36 & $*$ \\
\hline \multicolumn{6}{|l|}{ Typhus group } \\
\hline R. prowazekii (Madrid E) & $I, 111,523$ & 29.0 & 834 & 39 & {$[58]$} \\
\hline R. typhi (Wilmington) & $1,111,496$ & 28.9 & 838 & 39 & {$[26]$} \\
\hline \multicolumn{6}{|l|}{ Third group } \\
\hline R. bellii (RML369-C) & $1,522,076$ & 31.7 & 1,429 & 40 & {$[15]$} \\
\hline R. bellii (OSU 85-389) & $1,528,980$ & 31.6 & 1,476 & 36 & $*$ \\
\hline R. canadensis (McKiel) & $\mathrm{I}, 159,772$ & 31.1 & 1,093 & 36 & $*$ \\
\hline
\end{tabular}

* Unpublished genomes available in GenBank: R. akari (Hartford) [GenBank: NC 00988I],R. rickettsii (Sheila Smith) [GenBank: NC 009882], R. sibirica (246) [GenBank: NZ AABW00000000], R. bellii (OSU 85-389) [GenBank: NC 009883], and R. canadensis (McKiel) [GenBank: NC 009879].

mic element - 6 (RPE-6) familly. In this inverted fragment, $R$. africae exhibited 20 ORFs and 10 RPEs that were absent from R. conorii. Among these 20 ORFs, a cluster of 11 consecutive ORFs had orthologs in the 3'-extremity of the Tra cluster previously identified in the $R$. massiliae genome [29]. These 11 ORFs included traDF (ORF0650), a transposase (ORF0651), spoT15 (ORF0652), a split spoT13 (ORF0653/ORF0654), a split spoT6 (ORF0655/ ORF0656), a split signal transduction histidine kinase (ORF0657/ORF0658), dam2, a site-specific DNA adenine methylase (ORF0659), and ORF0660 of unknown function (Figure 3). In addition to the orthologs in R. massiliae, these genes had orthologs in similar clusters in $R$. felis, $R$. bellii, R. canadensis and O. tsutsugamushi but were absent from all other species. As in R. massiliae, R. bellii and $R$. canadensis, the $R$. africae cluster was bounded at its 3 '-end by a tRNA-Val, but, in contrast with these three species, neither an integrase with its attI site nor a tRNA-Val fragment marker of integration was present at the 5 ' end (Figure 3 ). The presence of a similar gene cluster inserted at the same position in several Rickettsia species, with a GC content different from that of the genome $(29.78 \% v s$ $32.4 \%$, respectively, in $R$. africae) suggests that it was acquired horizontally from a common ancestor and then transmitted vertically. In $R$. africae, an attC site, specific to integron-inserted gene cassettes, located at the 3'-end (coordinates: 687890-688018) of the spoT15 gene (ORF652), supports the role of integration in the insertion of this gene cluster. AttC sites were also identified in R. massiliae (coordinates: 743029-743145), R. felis (coordinates: 407889-408017), and $R$. bellii (coordinates 468143-468211). Nevertheless, the presence of transposases in all species and the fact that, in $R$. felis, nine of these genes are located in the pRF plasmid support the role of several genetic mechanisms at the origin of this cluster, possibly involving plasmids, integrons and transposons. In comparison with other species containing this gene cluster, $R$. africae had the smallest number of genes. In particular, it lacked most of the Tra cluster, with the exception of traDF, but retained three spoT genes, including two degraded to pseudogenes. In R. bellii and R. massiliae, tra genes were described as encoding components of a type IV secretion system (T4SS) for conjugal DNA transfer $[15,29]$. In terms of gene content, the $R$. africae cluster was more similar to those of $R$. felis and $R$. canadensis, with the loss of the Tra cluster, the conservation of spoT genes and the presence of pseudogenes, than to those of $R$. massiliae and R. bellii, in which the Tra cluster was intact but spoT genes were partially degraded. Such findings suggest that species-specific evolution of this gene cluster 


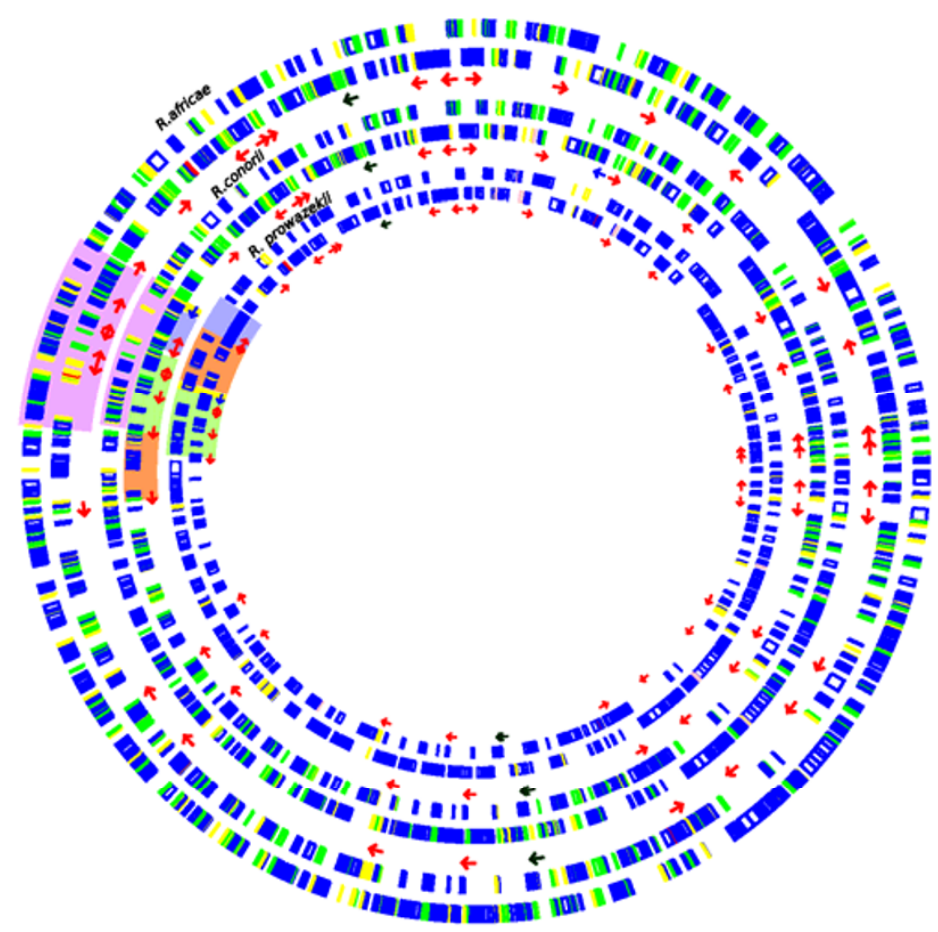

$$
\begin{array}{ll}
\text { I Genes common to all } 3 \text { rickettsiae } & \leftarrow \text { tRNA } \\
\text { I Genes common to } R \text {. africae/R. conorii } & \leftarrow \text { Ribosomal RNA } \\
\text { I Genes common to } R \text {. conorii/R. prowazekii } & \leftarrow \text { Other RNA } \\
\text { I Genes common to } R \text {. africae/R. prowazekii } & \\
\text { Specific genes } &
\end{array}
$$

\section{Figure I}

Circular representation of the genomes of $\boldsymbol{R}$. africae, $\boldsymbol{R}$. conorii, and $\boldsymbol{R}$. prowazekii based on data from GenBank entries [GenBank: NZ AAUY0I00000I], [GenBank: NC 003I03] and [GenBank: NC 000963], respectively. Protein coding genes common to all species are in blue; genes common to $R$. africae and $R$. conorii are in green; genes common to $R$. africae and $R$. prowazekii are in red; genes common to $R$. conorii and $R$. prowazekii are in pink and specific genes in each genomes are in yellow. Common genes are identified using best BLAST match. The region of rearrangement of the genome between $R$. africae and $R$. conorii is colored in purple; the regions of rearrangment between $R$. prowazekii and $R$. conorii are colored in orange, light green, yellow and light blue. Also represented are transfer RNAs (red arrows), ribosomal RNAs (dark arrows) and other RNAs.

occurred, which likely resulted from gene excisions in $R$. africae, $R$. felis and $R$. canadensis, or gene expansion by transposase duplication in R. massiliae.

In addition to the $\operatorname{traD}_{F}$ gene described above, the $R$. africae chromosome retained many of the components of the type IV secretion system (T4SS) involved in both DNA transfer and effector translocation in other bacteria [30], including virB1, virB2 (ORF0232), virB3 (ORF0128), virB4 (ORF0129, ORF1109), virB6 (ORF0130, ORF0131, ORF0132, ORF0133, ORF0134, ORF0135), virB8 (ORF0359, ORF0361), virB9 (ORF0358, ORF0362), virB10 (ORF0363), virB11(ORF0364), and virD4 (ORF0365). In addition, $R$. africae possessed a traX (ORF0816) and a split fimD (ORF0592/ORF0593/
ORF0594) gene but lacked other Tra cluster genes found in R. massiliae, R. felis, R. bellii and O. tsutsugamushi, such as traC and $\operatorname{traG}_{F}[15,28,29,31]$. Therefore, the Tra cluster was mostly eliminated from the R. africae, and, following a "use it or lose it" scheme, this species probably did not need a tra gene-linked conjugation system. In addition, the pRA plasmid did not contain genes encoding proteins involved in conjugation.

Six transposase-encoding genes were identified in the chromosome, including one split into two ORFs (ORF0955/ORF0956) and one present as a remnant and two in the pRA plasmid, including one present as a fragment. This contrasts with the large expansion of trans- 


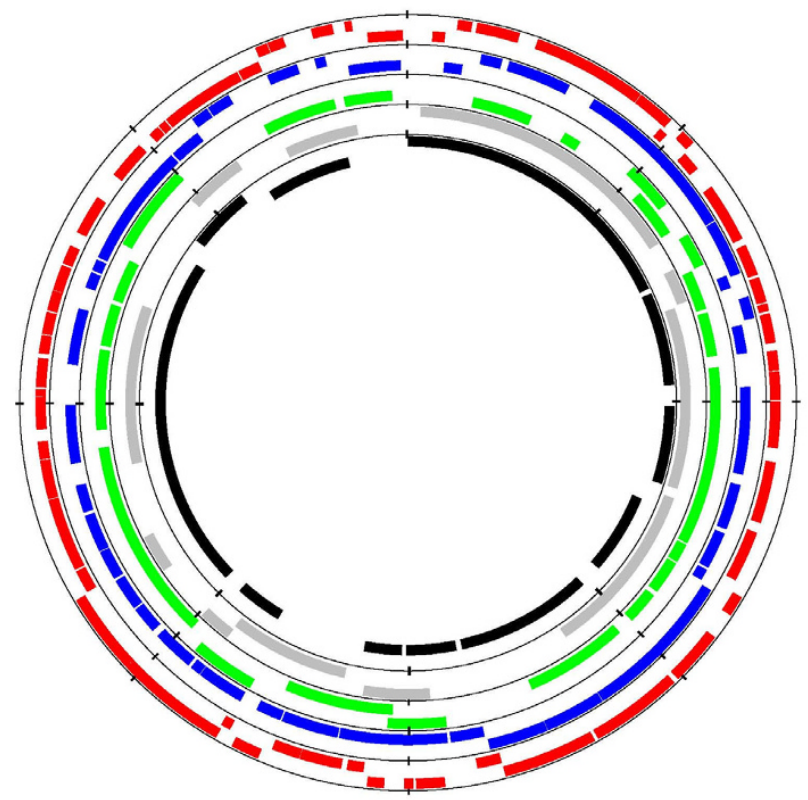

Figure 2

Circular representation of Rickettsia plasmids. A) The pRA plasmid: circles indicate (from the outside to the inside, on the reverse and forward strands) the GC skew, GC content, and ORFs; B) Rickettsia plasmids sequenced to date: circles indicate (from the outside to the inside, on the reverse and forward strands) $R$. felis pRF plasmid (red), $R$. felis pRF $\delta$ plasmid (blue), R. monacensis pRM plasmid (green), R. massiliae pRMa plasmid (grey), and R. africae pRA plasmid (black).

posases caused by gene duplications previously detected in $R$. felis and R. bellii $[15,28]$.

\section{Common rickettsial gene set and phylogeny}

When compared to eight other available rickettsial genomes, a total of 645 genes and 39 RNA-encoding genes of $R$. africae had orthologs in all genomes. In addition, another $32 \mathrm{R}$. africae genes had orthologs only in SFG rickettsiae and were either absent or remnant in TG rickettsiae. Consequently, we identified 645 genes as constituting the core gene set of all available rickettsial genomes and 700 ORFs as the core gene set of SFG rickettsiae. Following concatenation of the 645 core genes, a reliable phylogenetic organization (Figure 4) was obtained using three analysis methods that was consistent with previous phylogenetic studies of Rickettsia species [4,32-36].

In comparison with other Rickettsia genomes, $R$. africae had 242, 238 and 69 fewer genes than $R$. bellii, $R$. felis and $R$ massiliae, respectively, but 279, 260, 52, 23, 17, and 15 more genes than $R$. typhi, $R$. prowazekii, $R$. akari, R. rickettsii, R. sibirica, and R. conorii, respectively. When comparing the numbers of degraded genes (split + remnants), $R$. africae, with 127 degraded genes, had a significantly less degraded genome $\left(P<10^{-2}\right)$ than that of other spotted fever group rickettsiae including $R$. akari (176), R. conorii (196), R. massiliae (212), R. rickettsii (198) and R. sibirica
(199) (Table 1). It had, however, significantly more degraded genes than $R$. felis $\left(86, P<10^{-2}\right)$.

Transcription of genes conserved in R. africae but absent from highly pathogenic species

$R$. africae had 18 intact genes that were either absent or degraded in all three virulent species $R$. conorii, $R$. rickettsii and $R$. prowazekii. Of these, 12 encoded proteins of unknown functions (raf_ORF0036, raf_ORF0064, raf_ORF0391, raf_ORF0412, raf_ORF0414, raf_ORF0415, raf_ORF0445, raf_ORF0660, raf_ORF0758, raf_ORF0793, raf_ORF0876, and raf_ORF0884) (Figure 5) [see Additional file 4]. The remaining six genes encoded a plasmid maintenance system antidote protein (raf_ORF0424), the spoT15 gene (raf_ORF0652), a site-specific DNA adenine methylase (Dam2) (raf_ORF0659), an ankyrin repeat (raf_ORF0782), a putative integral membrane protein (raf_ORF0973), and a protein (RIG1002) exhibiting a high degree of amino acid sequence identity (>50\%) with proteins of $\gamma$-proteobacteria classified within the COG3943 as putative virulence proteins. When investigating the transcription of these 18 genes in $R$. africae grown at 28,32 and $37^{\circ} \mathrm{C}$, we observed a significantly higher transcription level at $37^{\circ} \mathrm{C}$ than at lower temperatures for two genes, raf_ORF414 and raf_ORF660. The 

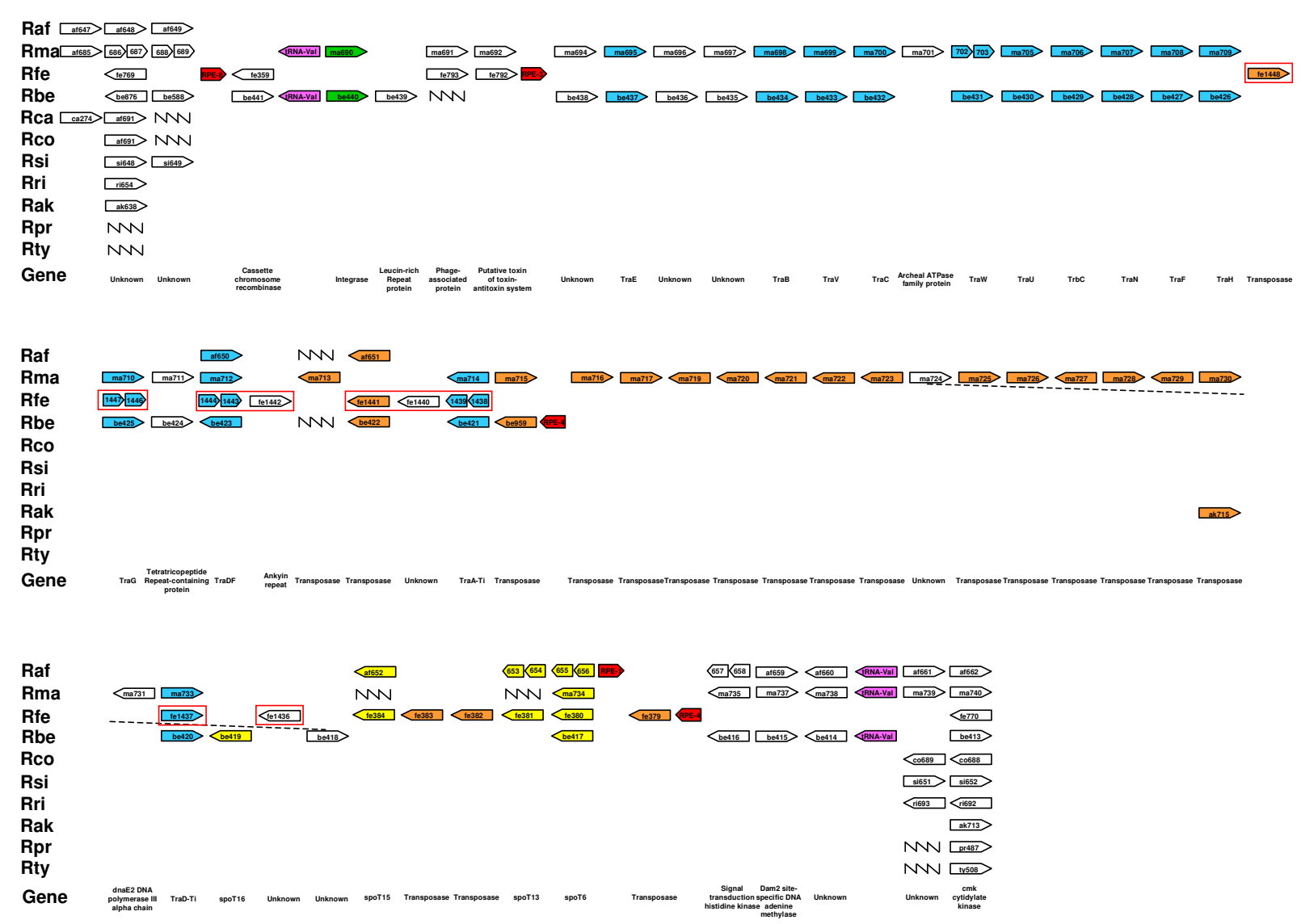

Figure 3

Presence of the tra gene cluster in Rickettsia species. Raf: $R$. africae; Rma: $R$. massiliae; Rfe: $R$. felis; Rbe: $R$. bellii; Rco: $R$. conorii; Rsi: R. sibirica; Rri: R. rickettsii; Rak: R. akari; Rpr: R. prowazekii; Rty: R. typhi.

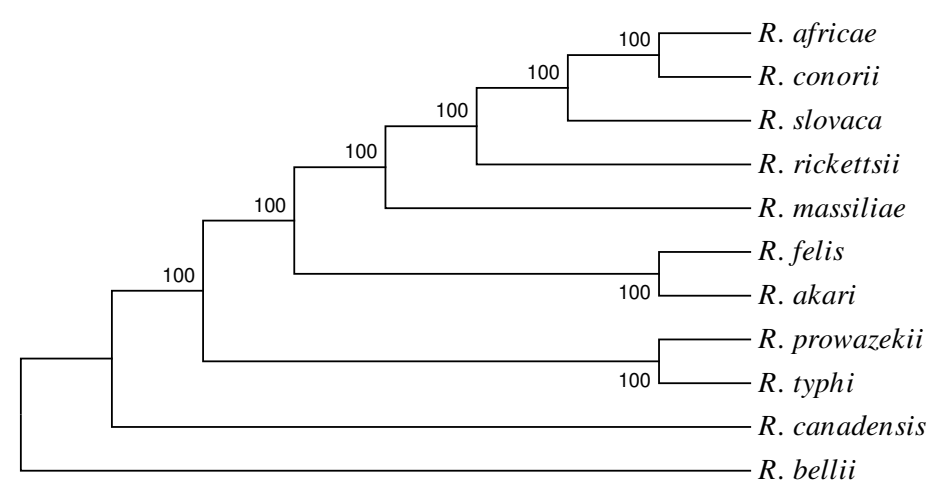

\section{Figure 4}

Phylogenetic tree inferred from the comparison of 645 concatenated Rickettsia core protein-coding genes. Similar organizations were obtained using both the maximum parsimony and neighbor joining methods. Bootstrap values are indicated at branch nodes. 


\begin{tabular}{|c|c|c|c|c|c|}
\hline $\begin{array}{l}\text { R. africae ORF } \\
\text { number }\end{array}$ & $\begin{array}{c}\text { Genes conserved by } R \text {. africae but degraded } \\
\text { by more pathogenic species }\end{array}$ & $\begin{array}{c}R . \\
\text { africae }\end{array}$ & $\begin{array}{c}R . \\
\text { conorii }\end{array}$ & $\begin{array}{c}R . \\
\text { rickettsii }\end{array}$ & $\begin{array}{c}R . \\
\text { prowazekii }\end{array}$ \\
\hline raf_ORF0652 & $\begin{array}{l}\text { spoT15; Guanosine polyphosphate } \\
\text { pyrophosphohydrolase/synthetase }\end{array}$ & & & & \\
\hline raf_ORF0659 & dam2; Site-specific DNA adenine methylase & & & & \\
\hline raf_ORF0660 & Unknown & & & & \\
\hline raf_ORF0036 & Unknown & & & & \\
\hline raf_ORF0064 & Unknown & & & & \\
\hline raf_ORF0391 & Unknown & & & & \\
\hline raf_ORF0412 & Unknown & & & & \\
\hline raf_ORF0414 & Unknown & & & & \\
\hline raf_ORF0415 & Unknown & & & & \\
\hline raf_ORF0424 & Plasmid maintenance system antidote protein & & & & \\
\hline raf_ORF0445 & Unknown & & & & \\
\hline raf_ORF0758 & Unknown & & & & \\
\hline raf_ORF0782 & Ankyrin repeat & & & & \\
\hline raf_ORF0793 & Unknown & & & & \\
\hline raf_ORF0876 & Unknown & & & & \\
\hline raf_ORF0884 & Unknown & & & & \\
\hline raf_ORF0973 & Putative integral membrane protein & & & & \\
\hline raf_ORF1002 & Putative virulence protein & & & & \\
\hline
\end{tabular}

\section{Figure 5}

Schematic representation of the genes conserved in $\boldsymbol{R}$. africae but lost by highly pathogenic rickettsiae. Genes highlighted in yellow are upregulated at $37^{\circ} \mathrm{C}$. The state of a gene is represented by a small box colored in green (full-length), blue (pseudogene), red (fragment), orange (remnant) or black (absent). Gene numbers are indicated in the left column.

former gene contained a putative protease domain site, but the latter had no known function.

\section{The $R$. africae plasmid}

The $R$. africae plasmid (Figure 2) is a new example of a plasmid in Rickettsia species, following those in R. felis [28], R. massiliae [29], R. monacensis [37], R. helvetica, R. peacockii, R. amblyommii and $R$. hoogstraalii [38]. This plasmid, named pRA, is smaller $(12,377 \mathrm{bp})$ than those of $R$. felis $(62,829$ bp and 39,263 bp long, for pRF and pRF $\delta$, respectively), $R$. monacensis $(23,486 \mathrm{bp})$, and $R$. massiliae $(15,286 \mathrm{bp})$. The pRA plasmid is predicted to contain 11 genes, 6 of which $(54 \%)$ have homologs in public databases and are associated with functional attributes. These six genes encode for a chromosomal replication initiator DnaA-like protein (ORF1260), a site-specific recombinase (ORF1262), two contiguous transposases exhibiting $100 \%$ sequence similarity (ORF1263 and 1264) but with one (ORF1263) shorter than the other, the auto-transporter protein SCA12 (ORF1268), and a ParA-like plasmid stability protein (ORF1270). Five genes (ORFs 1260, $1263,1264,1269$ and 1270) have orthologs in the R. massiliae plasmid, six have orthologs in the R. felis plasmids
(ORF1260, 1263, 1264, 1268, 1269 and 1270), and three have orthologs in the R. monacensis plasmid (ORF1260, ORF1268, and ORF1270). The presence of two genes (ORF1260 and 1270) conserved in plasmids from four species suggests that these plasmids have a common origin. The presence of two almost identical successive transposases in $R$. africae matching a single gene in $R$. massiliae and $R$. felis suggests a duplication event in the former species. The pRA plasmid lacks heat shock protein-encoding genes found in other rickettsial plasmids. In contrast, ORF1262, a site-specific recombinase, is absent from other species. Its closest phylogenetic neighbour is a sitespecific recombinase from Magnetospirillum magnetotacticum, a high G-C content $\alpha$-proteobacterium living in aquatic environments [39]. The sca12 gene (ORF) found intact in $R$. africae pRA was absent from the $R$. massiliae and $R$. monacensis plasmids and present but fragmented within $R$. felis pRF, but it was absent from pRF $\delta$ as well all other Rickettsia species.

As outlined by Baldridge et al. [38], the plasmid content of a Rickettsia species may vary according to the passage history of rickettsial strains. When estimating the prevalence 
of the plasmid among $R$. africae strains, we detected it in the 22 tested isolates from South Africa and in the 48 eschar biopsies from patients with ATBF contracted in the same country and in 20/32 R. africae-positive Amblyomma ticks [see Additional files 5 and 6]. Therefore, it appears from these results that, depending on the geographic location, the plasmid of $R$. africae may be unstable. Whether the plasmid has been lost by PCR-negative strains or cannot be amplified with the primers we used is as yet unknown. Such inter-strain differences in plasmid content were also observed in $R$. felis (Unpublished data).

\section{Stress response}

Rickettsiae live intracellularly in both arthropod and mammal hosts. This implies that periods of tick starvation and feeding cause bacterial dormancy and multiplication following reactivation [40]. As a consequence, and despite their obligate intracellular location, rickettsiae may face, and thus have to adapt to, highly variable and extreme environmental conditions. Known as the stringent response, this bacterial adaptation to nutritional stress has been described to be mediated by the accumulation of guanosine nucleotides pppGpp (guanosine 3'-diphosphate 5'-triphosphate) and ppGpp (guanosine 3'-diphosphate 5'-diphosphate) [41]. Accordingly, the transcriptional analysis of $R$. conorii exposed to a nutrient deprivation was characterized by the up-regulation of $g m k$ and of genes from the spoT family, suggesting a role for these nucleotides as effectors of the stringent response $[42,43]$. The $R$. africae genome exhibited eight spoT genes phylogenetically classified within two major clades [see Additional file 7]. The largest clade included spoT genes with hydrolase activity $(1-10,14,15,17-21)$, while the second included those with a synthetase domain. With eight genes, $R$. africae had more spoT genes than $R$. rickettsii (5 genes), $R$. conorii (4), R. sibirica (4), R. akari (7), $R$. canadensis (5), $R$. typhi (4) and $R$. prowazekii (1) but fewer genes than $R$. felis (14) and R. bellii (10) [see Additional file 8]. Altogether, our data suggest that $R$. africae is more regulated than more pathogenic species.

\section{Infection of mammal hosts}

The $R$. africae genome encoded rOmpA (or Sca0) and rOmpB (or Sca5), two surface-exposed and immunodominant proteins belonging to the paralogous "surface cell antigen" (SCA) family and known in Rickettsia species to be responsible for antigenic differences between species [1] and to elicit an immune response in patients [44]. Experimental studies suggested that these two auto-transporter proteins could function as adhesins $[10,11,45,46]$. In addition, another eight SCA-encoding genes were found in the genome. These 10 genes were represented by 22 ORFs due to partial degradation of some of the paralogs [see Additional file 8]. Among the 17 SCA-encoding genes detected in Rickettsia species [47], R. africae had sim- ilar sets of conserved ( $s c a 0-2,4$ and 5), degraded (sca3, $8-10$ and 13) and absent (sca6, 7, 11, 14-17) sca genes as $R$. conorii and $R$. rickettsii. In addition to these 10 SCAencoding genes, $R$. africae exhibited a degraded sca9 gene and a complete sca 12 gene carried by the pRA plasmid, only shared with $R$. felis, where it was also found partially degraded on the pRF plasmid. The sca 12 genes from both species were grouped into a distinct cluster close to the sca1, 2 and 6 genes [see Additional file 9]. This result further supports a common origin of the pRA and pRF plasmids.

A proteomic approach recently allowed the identification of two paralogous proteins encoded by the genes RC1281RC1282 and RP827-RP828, as putative adhesins Adr1 and Adr2. These proteins may be key actors for entry and infection in both $R$. conorii and $R$. prowazekii [11]. Both proteins are ubiquitously present within the Rickettsia genus [4]. Their presence within the $R$. africae genome (ORF1174 + ORF1175) [see Additional file 10] reinforces their suspected key role in rickettsial life.

Both pld and $t l y C$, encoding phospholipase $\mathrm{D}$ [8] and hemolysin C [12], respectively, which play a role in phagosomal escape $[13,48]$, were conserved in the $R$. africae genome (ORF1161 and ORF1039, respectively). This bacterium also exhibited genes encoding other proteins with membranolytic activity, including tlyA (hemolysin A) and pat1 (patatin-like phospholipase) $[12,49]$. As expected, the genome of $R$. africae has a rickA gene (ORF0824) orthologous to all rickettsial rickA genes and coding a protein activating the Arp $2 / 3$ complex, whose nucleation triggers actin polymerisation [50] [see Additional file 11]. The Rick A protein in R. africae is slightly different from those of other species, with a phenylalanine instead of a serine within the G-actin-binding site, an ENNIP [PS] motif repeated twice instead of four times in the central proline-rich region of the protein [see Additional file 11], and an aspartate and an isoleucine instead of an asparagine and an alanine or valine, respectively, in the carboxy-terminal region. Despite these differences, the RickA protein of $R$. africae appeared to be functional as demonstrated by its ability to polymerize actin and multiply intranuclearly (Figure 6).

Sixteen vir gene paralogs were found in the R. africae genome. Virulence genes of the vir family belong to the type IV secretion machinery, a system that allows the delivery of virulence factors from bacterial and eukaryotic host membranes to the cytoplasm of the host cell [51]. All 16 genes were found to be intact and common to all Rickettsia genomes with the exception of virB6-2 in R. africae and virB6-5 in R. massiliae [see Additional file 8]. In both species, these genes were split into two ORFs. Phylogenetic analysis of the virB6-2 gene distinguished clearly the 


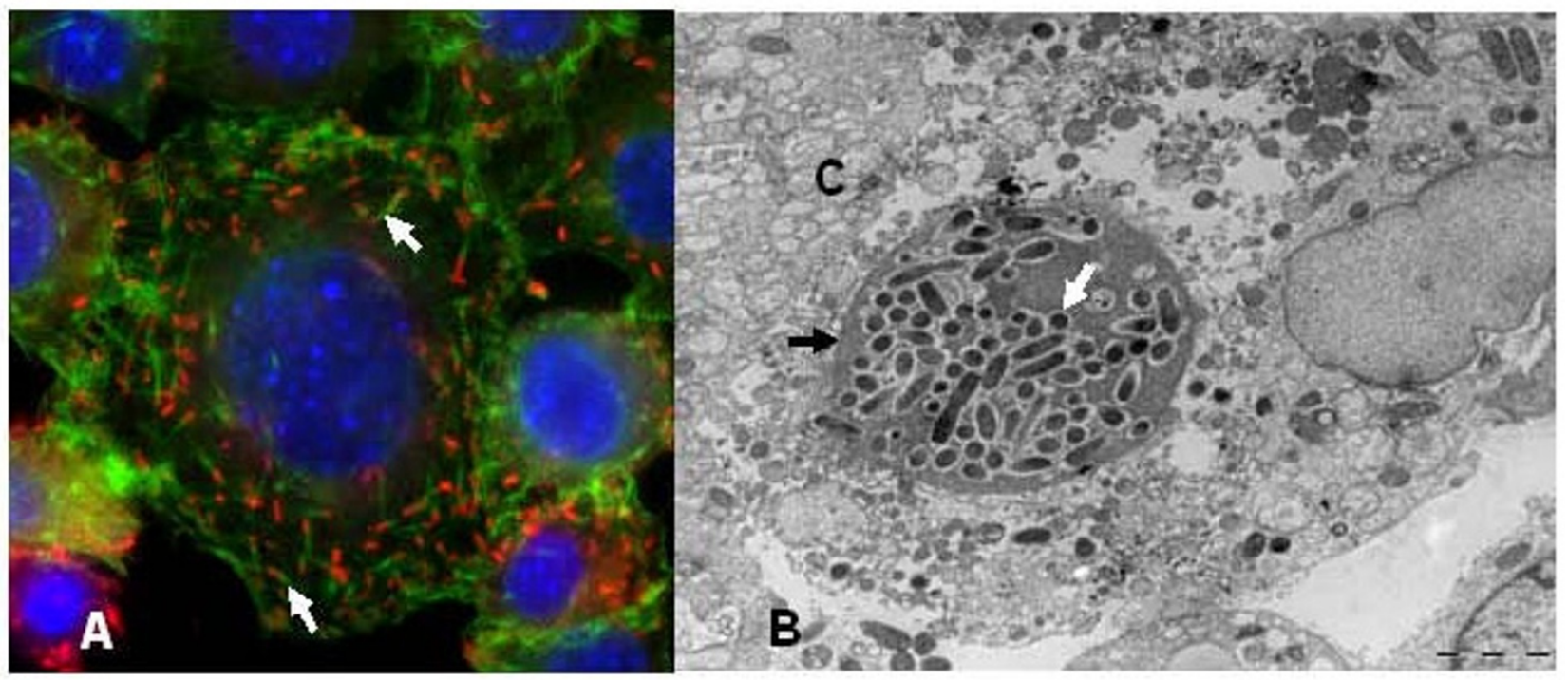

Figure 6

Intracellular motility of $\boldsymbol{R}$. africae. A) Actin tail formation by $R$. africae. L-929 cells were infected with $R$. africae, fixed and stained with fluorescent phalloidin (green) and a polyclonal antibody against $R$. africae and visualized using anti-rabbit-Alexa549 as a secondary antibody (red). The white arrows show actin tails. B) $R$. africae in the cytoplasm and nucleus of L-929 cells. $C=$ cytoplasm; black arrow = nucleus; white arrows $=R$. africae bacilli. Transmission electron microscopy. Scale bar $=5 \mu \mathrm{m}$.

SFG and TG and showed that the R. africae VirB6-2 protein is phylogenetically closer to that of $R$. sibirica [see Additional file 12].

\section{Clonality of $\mathbf{R}$. africae}

Of the 155 Amblyomma ticks tested, 139 (89.6\%) were PCR-positive for R. africae [see Additional file 5]. Therefore, infection rates of Amblyomma ticks with $R$. africae may be higher than previously described [21,22,52], which suggests an extreme fitness of this rickettsia for its vector. In addition, such infection rates are the highest among Rickettsia species [see Additional file 13].

Using MST, PCR products of the expected sizes were obtained from the $d k s A$-xerC, mppA-purC and $r p m E$ $\mathrm{tRNA}^{\mathrm{fMet}}$ intergenic spacers from all tested specimens. Sequences obtained from these amplicons were in all cases identical to those previously obtained for $R$. africae [GenBank: DQ008280], [GenBank: DQ008301], and [GenBank: DQ008246], for the dksA-xerC, mppA-purC and rpmE-tRNA ${ }^{\text {fMet }}$ spacers, respectively). This is the first rickettsia demonstrated to be clonal. Other tested Rickettsia species, including $R$. conorii (31 MST genotypes out of 39 strains tested [53]), R. massiliae (2/7 [24]), R. sibirica (3/3 [24]), and $R$. felis (3/6 [24]), were significantly more genetically variable than $R$. africae ( $p<10^{-2}$ in all cases).

\section{Discussion}

Using a comparative study of rickettsial genomes, we found that virulence in Rickettsia species is not correlated with acquisition of foreign DNA but may rather result from a reduction in regulation due to genome decay $[6,23]$. Comparative genomics sheds light on a much wider spectrum of virulence acquisition mechanisms in bacteria than initially thought [54]. Based on the examples of enterobacteria and staphylococci, gain in pathogenicity in bacteria was mainly thought to result from horizontal gene transfer, either directly or through mobile genetic elements $[55,56]$. However, a recent study of Rickettsia species associated with arthropods, insects, leeches and protists clearly demonstrated that horizontal gene transfer was a rare event within this genus [5]. In addition, genomic studies demonstrated that rickettsiae are undergoing genome decay, affecting in priority horizontallyacquired genes [57], and that there is no association between pathogenicity and acquisition of virulence markers [6]. In fact, the genome of the most virulent species, $R$. prowazekii [58], is a subset of the less pathogenic species $R$. conorii [23], thus highlighting a paradoxical relationship between smaller genome size and higher pathogenicity. Careful comparison of the $R$. prowazekii and $R$. typhi genomes also demonstrated that the former species, more pathogenic than the latter, had a more decayed genome despite a 12-kb insertion that likely resulted from a single genetic event [59]. 
When investigating the genomic characteristics associated with the milder virulence of $R$. africae, we first ruled out a potential role of the plasmid by the fact that it is unstable in this species. Then, we compared the gene contents of $R$. africae with $R$. conorii, $R$. rickettsii, and $R$. prowazekii, which exhibit a higher pathogenicity in humans and their arthropod hosts. We observed that $R$. africae showed no gene loss but had 18 genes fully conserved that were either absent or degraded in the other species (Figure 5). We speculated that, because $R$. africae had more intact genes than more virulent species, some of these genes may be involved in maintaining a low virulence level. Such a behavior may not be unique to rickettsiae. It was found that gene knockout resulted in increased virulence in $M y c$ oplasma, Streptococcus pyogenes, and Vibrio cholerae [60-62]. In M. ulcerans, genome reduction was also linked to gain in virulence [63]. It emerges as a concept that virulence may be increased by gene loss [54]. We assume that a similar phenomenon may happen in rickettsiae, and that inactivation of some genes may deregulate the control of bacterial multiplication, in particular during the reactivation phenomenon following warming, thus enhancing pathogenesis.

Among the 18 putative candidate genes unique to $R$. africae, we identified only two genes (raf_ORF414 and raf_ORF660) that were significantly more transcribed at $37^{\circ} \mathrm{C}$ than at lower temperatures. Of these, one (raf_ORF414) encoded a protein that had a putative protease domain. A protease was previously shown in Vibrio cholerae to be a virulence repressor [60]. However, whether this differentially-transcribed protease plays a role in virulence repression in $R$. africae is as yet unknown. In contrast, the spoT15 gene (raf_ORF652) unique to $R$. africae was not upregulated, and this species retained another two spoT pseudogenes (raf_ORF653-654 and raf_ORF655-656) that were completely lost by other species. SpoT genes, effectors of the stringent response, were shown to play a major role in adaptation to stress in $R$. conorii, in particular when subjected to abrupt temperature variations similar to those occurring during a tick blood meal [42]. R. africae, however, has more spoT genes than $R$. conorii or $R$. rickettsii and does not show any modification of expression of its specific spoT15 gene during temperature variations. We speculate that higher regulation ability in $R$. africae is linked to lower pathogenicity.

In addition, when compared to other tick-borne Rickettsia species, $R$. africae exhibited several unique characteristics. First, this species is extremely successful and fit: it is highly adapted and harmless to its tick host, being efficiently transmitted both transtadially and transovarially in Amblyomma sp. ticks, which consequently act as efficient reservoirs [64]. In contrast, $R$. rickettsii $[65,66]$ and $R$. conorii [67] have a negative effect on their tick vectors in experimental models. As a result, the prevalence of $R$. africae in its host ticks is higher than that of most other rickettsiae. Similarly, $R$. africae is less pathogenic for humans than other SFG species such as $R$. conorii and R. rickettsii, in particular because the infection is never lethal [17]. This observation was later supported by the demonstration that inoculation eschars in ATBF were histologically different from those in MSF [68]. In particular, in contrast with other SFG rickettsioses where eschars are characterized by perivascular infiltration of $\mathrm{T}$ cells and macrophages, with some B lymphocytes and few polymorphonuclears, the vasculitis in ATBF is made of a large infiltrate of neutrophils causing an extensive cutaneous inflammation and necrosis [see Additional file 14] [68]. Such a local reaction, in addition to the few $R$. africae cells detected in eschars [68], suggests that the bacterium replicated poorly in human tissues. Second, $R$. africae has significantly fewer degraded genes than other SFG species $\left(p<10^{-2}\right)$, except $R$. felis. Specifically, this characteristic suggests that $R$. africae is undergoing a slower degradation process than other rickettsiae. Third, the identification of a single MST genotype among 102 strains suggested that $R$. africae was clonal $[24,69]$. This contrasted with the variable plasmid content of this species. Originally thought to be absent in Rickettsia species, plasmids have been detected in eight species to date $[28,29,37,38]$, and their plasmid content may exhibit intraspecies variability. In $R$. felis, two plasmid forms have been sequenced [28], and Baldridge et al. found two plasmids in both $R$. peacockii and $R$. amblyommii [38]. In addition, these authors showed that $R$. peacockii lost its plasmids during long-term serial passages in cell culture [38]. In $R$. africae, the pRA plasmid may also be unstable, as shown by the absence of plasmid detection in 12/32 Amblyomma ticks tested. This plasmid encodes 11 ORFs, two of which are common to R. felis, R. massiliae and R. monacensis plasmids [see Additional file 1], which strongly suggests a common source for these mobile elements. We suspect that rickettsial plasmids and Tra clusters are vertically inherited but are apparently unstable and are currently degrading.

\section{Conclusion}

Based on its genome and lifestyle, we suspect that the clonal $R$. africae is more regulated and more specifically adapted to its host and warm environment than other tick-associated rickettsiae. We speculate that losing this regulation, as observed in several intracellular pathogens, is a critical cause of virulence [6]. Further transcriptomic analysis of $R$. africae and other Rickettsia species grown at various temperatures is currently ongoing to identify putative other candidate genes involved in stress response. 


\section{Methods \\ Genome Sequencing}

Bacterial purification and DNA extraction

In this study, we used $R$. africae ESF-5 strain, CSUR R15 (Collection de souches de l'Unité des Rickettsies, Marseille, France), which was isolated in an Amblyomma variegatum tick collected from cattle in the Shulu province of Ethiopia in 1966 [27]. R. africae was cultivated in Vero cells growing in MEM with 4\% fetal bovine serum supplemented with $5 \mathrm{mM}$ L-glutamine. Bacterial purification, DNA extraction and pulsed-filed gel electrophoresis were performed as described in Additional file 15 [see Additional file 15].

\section{Shotgun sequencing of $\mathrm{R}$. africae genome}

Three shotgun genomic libraries were made by mechanical shearing of the DNA using a Hydroshear device (GeneMachine, San Carlos, CA, USA). Sequence blunt ends, to which the BstXI adaptator was linked, were obtained using the T4 DNA polymerase (New England Biolabs). Fragments of 3, 5, and $10 \mathrm{~kb}$ were separated on a preparative agarose gel (FMC, Rockland, ME, USA), extracted using the Qiaquick kit (Qiagen, Hilden, Germany), and ligated into a high copy-number vector pCDNA2.1 (Invitrogen, Carlsbad, CA, USA) for the two smaller inserts and into the low copy-number vector pCNS [28] for the largest inserts. Further details are available in Additional file 15 [see Additional file 15].

\section{Annotation}

We predicted protein-coding genes (ORFs) using SelfID as previously described [15]. Functional assignments for the ORFs were based on database searches using BLAST [70] against UniProt [71], NCBI/CDD [72], and SMART [73] databases. In most cases, we applied an E-value threshold of 0.001 for the database searches to retrieve homologues. Detailed analyses using multiple sequence alignments and phylogenetic reconstructions were carried out to assign putative functions to the ORFs, when needed. Orthologous gene relationships between $R$. africae and other Rickettsia species were approximated using the best reciprocal BLAST match criterion. The numbers of transposases, ankyrin/tetratricopeptide repeat-containing genes, and integrases were computed using RPS-BLAST with NCBI/CDD entries related to those domains with a $10^{-5}$ E-value threshold. tRNA genes were identified using tRNAscan-SE [74]. To identify Rickettsia palindromic elements, we used hidden Markov models [75] based on the previously identified Rickettsia palindromic element sequences. ClustalW [76], T-coffee [77], and MUSCLE [78] were used to construct multiple sequence alignments. Toxin-antitoxin genes were identified using the Rasta-Bacteria software http://genoweb.univ-rennes1.fr/ duals/RASTA-Bacteria.

\section{Phylogenetic analysis}

We based our analysis on the 645 complete orthologous genes found by Blast programmes in all Rickettsia genomes [70]. Subsequently, the amino acid sequences of these 645 proteins were concatenated for each genome and multiple alignment was performed using the Mafft software [79]. Gapped positions were removed. The maximum parsimony and neighbor joining trees were constructed using the MEGA 3.1 software [80].

\section{Clonal origin of $\mathbf{R}$. africae}

We examined $R$. africae within 155 Amblyomma sp. ticks and eggs from various geographical origins [see Additional file 5]. These included 80 adults (40 male and 40 female), 40 larvae, 15 nymphs and 20 eggs. PCR amplification of the traD gene was performed using the R. africaespecific primer pair traD-F (5'-caatgcttgatctattggtag-3') and traD-R (5'-cttcctttctctaagctatgc-3') and the probe traD-probe (5'-FAM-ttatggtgctaactccatgcgtgatg-TAMRA$\left.3^{\prime}\right)$. The presence of the plasmid was estimated using the primer pair $1267 \mathrm{~F}$ ( $5^{\prime}$-ccagccattaccgtaatcac-3') and $1267 \mathrm{R}$ (5'-tagtgccttatactcaagttc-3') and the probe 1267-probe (5'FAM-gcagaaagtgattaaggcgatcagctg-TAMRA-3') that is able to detect ORF 1267 encoding a protein of unknown function specific to the plasmid. The presence of the plasmid was examined in 22 strains obtained from patients who contracted the disease in South Africa and maintained in the CSUR [see Additional file 6], in PCR-positive eschar biopsies from another 48 patients who developed ATBF following a trip to South Africa, and in 32 Amblyomma sp. ticks found positive for $R$. africae, using the abovedescribed PCR assay [see Additional file 5]. To evaluate the genetic diversity of $R$. africae, we used the multi-spacer typing (MST) method as previously described [53]. This method has been described as the most discriminatory genotyping tool at the intraspecies level in Rickettsia sp. [53]. We applied this method to the aforementioned 22 human $R$. africae strains, 48 eschar biopsies, and 32 Amblyomma sp. ticks from Sudan (3), Madagascar (3), Mali (3), Niger (6), Central African Republic (6), Ivory Coast (3), Guadeloupe (4), Martinique (2), and St Kitts and Nevis (2) [see Additional file 5]. The obtained sequences were compared to those available in GenBank, and the MST genotypes were determined as previously described [53].

\section{Transcription of genes conserved in R. africae but absent from highly pathogenic species}

To evaluate the transcription of the 18 genes conserved by $R$. africae and degraded in highly pathogenic species, we designed specific primer pairs and probes for each gene and tested the transcription of these genes by RT-PCR on RNA extracted from $R$. africae- infected Vero cells cultivated at 32 and then at $37^{\circ} \mathrm{C}$ and in XTC cells at 28 and 
$32^{\circ} \mathrm{C}$. Experimental protocols are detailed in Additional file 15 [see Additional file 15].

\section{Authors' contributions}

PEF and DR designed the study, drafted the manuscript, and gave final approval of the submitted version; KE, QL, CR, BG, PR, CR, PP, and SA performed experiments, drafted the manuscript and gave final approval of the submitted version.

\section{Additional material}

\section{Additional file 1}

Gene content of the $\mathbf{R}$. africae plasmid. GenBank accession number sare indicated in square brackets. The Table includes a comparison of rickettsial plasmid contents.

Click here for file

[http://www.biomedcentral.com/content/supplementary/1471-

2164-10-166-S1.doc]

\section{Additional file 2}

$\mathrm{R}$. africae gene content. The Table includes the gene content of the $\mathrm{R}$. africae genome.

Click here for file

[http://www.biomedcentral.com/content/supplementary/14712164-10-166-S2.doc]

\section{Additional file 3}

Inversion observed by alignment of the $\mathrm{R}$. africae (up) and $\mathrm{R}$. conorii (down) genomes. The Figure shows an alignment of the $\mathrm{R}$. conorii and $\mathrm{R}$. africae genomes.

Click here for file

[http://www.biomedcentral.com/content/supplementary/1471-

2164-10-166-S3.ppt]

\section{Additional file 4}

Schematic representation of the genes diversely conserved in $\mathrm{R}$. africae in comparison with highly pathogenic rickettsiae. The state of a gene is represented by a small box colored in green (full-length), blue (pseudogene), red (fragment), orange (remnant) or black (absent). Gene numbers are indicated in the left column. The Figure shows the gene distribution in $\mathrm{R}$. africae by comparison with highly pathogenic rickettsiae.

Click here for file

[http://www.biomedcentral.com/content/supplementary/1471-

2164-10-166-S4.ppt]

\section{Additional file 5}

PCR-detection of R. africae and in Amblyomma ticks. Results are indicated as number of ticks positive/number tested. The Table includes the results from PCR detection of the $\mathrm{R}$. africae chromosome and plasmid in ticks.

Click here for file

[http://www.biomedcentral.com/content/supplementary/1471-

2164-10-166-S5.doc]

\section{Additional file 6}

Rickettsia africae strains used in this study. The table lists all R. africae strains used in this study.

Click here for file

[http://www.biomedcentral.com/content/supplementary/1471-

2164-10-166-S6.doc]

\section{Additional file 7}

Phylogenetic tree showing the organization of spoT genes in Rickettsia species. Phylogenetic relationships were inferred from aligned sequences using the Mega3.1 software with the Neighbor-Joining method. Bootstrap values are indicated at the nodes. The Figure is a phylogenetic tree showing the organization of spoT genes in Rickettsia species. Click here for file

[http://www.biomedcentral.com/content/supplementary/14712164-10-166-S7.ppt]

\section{Additional file 8}

R. africae ORFs compared to other available Rickettsia genomes. The table details the distribution of $\mathrm{R}$. africae ORF in other rickettsial genomes.

Click here for file

[http://www.biomedcentral.com/content/supplementary/1471-

2164-10-166-S8.doc]

\section{Additional file 9}

Phylogenetic tree showing the organization of sca genes in Rickettsia species. Phylogenetic relationships were inferred from aligned sequences using the Mega3.1 software with the Neighbor-Joining method. Bootstrap values are indicated at the nodes. The Figure is a phylogenetic tree showing the organization of sca genes in Rickettsia species.

Click here for file

[http://www.biomedcentral.com/content/supplementary/1471-

2164-10-166-S9.ppt]

\section{Additional file 10}

Phylogenetic tree showing the organization of adr genes in Rickettsia species. Phylogenetic relationships were inferred from aligned sequences using the Mega3.1 software with the Neighbor-Joining method. Bootstrap values are indicated at the nodes. The Figure is a phylogenetic tree showing the organization of $\operatorname{adr}$ genes in Rickettsia species.

Click here for file

[http://www.biomedcentral.com/content/supplementary/1471-

2164-10-166-S10.ppt]

\section{Additional file 11}

Features of RickA repeat proline-rich motif in $\mathrm{R}$. africae and other SFG rickettsiae. The motif " [EDGKQG]- [NS]-N- [IV]-

[PSLTR] $(0,28) "$ was used to extract these repeats using a PatternMatchingtool. The table details RickA repeat proline-rich motifs in $\mathrm{R}$. africae and other SFG rickettsiae.

Click here for file

[http://www.biomedcentral.com/content/supplementary/14712164-10-166-S11.doc] 


\section{Additional file 12}

Phylogenetic tree showing the organization of virB6-2 genes in Rickettsia species. Phylogenetic relationships were inferred from aligned sequences using the Mega3.1 software with the Neighbor-Joining method. Bootstrap values are indicated at the nodes. The Figure is a phylogenetic tree showing the organization of virB6-2 genes in Rickettsia species. Click here for file [http://www.biomedcentral.com/content/supplementary/14712164-10-166-S12.ppt]

\section{Additional file 13}

Comparison of epidemiological and clinical characteristics of Rickettsia species. The table includes data about the epidemiological and clinical characteristics of Rickettsia species.

Click here for file

[http://www.biomedcentral.com/content/supplementary/1471-

2164-10-166-S13.doc]

\section{Additional file 14}

Immunohistochemical detection of $\mathrm{R}$. africae (arrows) in the inoculation eschar of a patient with ATBF (monoclonal rabbit anti-R. africae antibody used at a dilution of 1:1,000 and hematoxylin counterstain; original magnification $\times 250$ ). The Figure shows the presence of $\mathrm{R}$. africae in the inoculation eschar of a patient with ATBF, revealed by immunohistochemistry.

Click here for file

[http://www.biomedcentral.com/content/supplementary/14712164-10-166-S14.ppt]

\section{Additional file 15}

Supplementary material and methods. The data provided include detailed material and methods that were used for the genome sequencing and sequence analysis of $\mathrm{R}$. africae.

Click here for file

[http://www.biomedcentral.com/content/supplementary/14712164-10-166-S15.doc]

\section{Acknowledgements}

This work was funded by the Network of Excellence "EuroPathoGenomics".

\section{References}

I. Raoult D, Roux V: Rickettsioses as paradigms of new or emerging infectious diseases. Clin Microbiol Rev 1997, 10:694-7I9.

2. Parola $\mathrm{P}$, Paddock $C D$, Raoult $\mathrm{D}$ : Tick-borne rickettsioses around the world: emerging diseases challenging old concepts. Clin Microbiol Rev 2005, I 8:719-756.

3. Perlman SJ, Hunter MS, Zchori-Fein E: The emerging diversity of Rickettsia. Proc Biol Sci 2006, 273:2097-2106.

4. Blanc G, Ogata H, Robert C, Audic S, Suhre K, Vestris G, et al.: Reductive genome evolution from the mother of Rickettsia. PLOS Genet 2007, 3: el4.

5. Weinert LA, Werren JH, Aebi A, Stone GN, Jiggins FM: Evolution and diversity of Rickettsia bacteria. BMC Biol 2009, 7:6.

6. Darby AC, Cho NH, Fuxelius HH, Westberg J, Andersson SG: Intracellular pathogens go extreme: genome evolution in the Rickettsiales. Trends Genet 2007, 23:51 I-520.

7. Sallstrom B, Andersson SG: Genome reduction in the alpha-Proteobacteria. Curr Opin Microbiol 2005, 8:579-585.

8. Renesto P, Dehoux P, Gouin E, Touqui L, Cossart P, Raoult D: Identification and characterization of a phospholipase D-superfamily gene in rickettsiae. J Infect Dis 2003, I 88: I276- I 283.
9. Hayes SF, Burgdorfer W: Reactivation of Rickettsia rickettsii in Dermacentor andersoni ticks: an ultrastructural analysis. Infect Immun 1982, 37:779-785.

10. Uchiyama T: Adherence to and invasion of Vero cells by recombinant Escherichia coli expressing the outer membrane protein rOmpB of Rickettsia japonica. Ann N Y Acad Sci 2003, 990:585-590.

II. Renesto P, Samson L, Ogata H, Azza S, Fourquet P, Gorvel JP, et al.: Identification of two putative rickettsial adhesins by proteomic analysis. Res Microbiol 2006, I 57:605-6I2

12. Whitworth T, Popov VL, Yu XJ, Walker DH, Bouyer DH: Expression of the Rickettsia prowazekii pld or tlyC gene in Salmonella enterica serovar Typhimurium mediates phagosomal escape. Infect immun 2005, 73:6668-6673.

13. Teysseire N, Boudier JA, Raoult D: Rickettsiaconorii entry into vero cells. Infect Immun 1995, 63:366-374.

14. Gouin E, Gantelet H, Egile C, Lasa I, Ohayon H, Villiers V, et al.: A comparative study of the actin-based motilities of the pathogenic bacteria Listeria monocytogenes, Shigella flexneri and Rickettsia conorii. I Cell Sci 1999, I I 2: I697-I708.

15. Ogata H, La Scola B, Audic S, Renesto P, Blanc G, Robert C, et al: Genome sequence of Rickettsia bellii illuminates the oole of amoebae in gene exchanges between intracellular pathogens. PLoS Genet 2006, 2:e76.

16. Tissot-Dupont H, Brouqui P, Faugere B, Raoult D: Prevalence of antibodies to Coxiella burnetii, Rickettsia conorii, and Rickettsia typhi in seven African countries. Clin Infect Dis 1995, 21:।126-II33.

17. Raoult D, Fournier PE, Fenollar F, Jensenius M, Prioe T, de Pina JJ, et al.: Rickettsia africae, a tick-borne pathogen in travelers to sub-Saharan Africa. N Engl J Med 200I, 344: I504-I5I0.

18. Jensenius M, Fournier PE, Kelly P, Myrvang B, Raoult D: African tick bite fever. Lancet Infect Dis 2003, 3:557-564.

19. Jensenius M, Fournier PE, Vene S, Hoel T, Hasle G, Henriksen AZ, et al:: African tick bite fever in travelers to rural sub-Equatorial Africa. Clin Infect Dis 2003, 36:14II-1417.

20. Jensenius M, Hoel T, Raoult D, Fournier PE, Kjelshus H, Bruu AL, et al:: Seroepidemiology of Rickettsia africae infection in Norwegian travellers to rural Africa. Scand J Infect Dis 2002, 34:93-96.

21. Parola P, Inokuma H, Camicas JL, Brouqui P, Raoult D: Detection and identification of spotted fever group rickettsiae and ehrlichiae in African ticks. Emerg Infect Dis 2001, 7:1014-1017.

22. Tissot-Dupont $\mathrm{H}$, Cornet JP, Raoult D: Identification of rickettsiae from ticks collected in the Central African Republic using the polymerase chain reaction. Am J Trop Med Hyg 1994, 50:373-380.

23. Ogata $H$, Audic S, Renesto-Audiffren P, Fournier PE, Barbe V, Samson $D$, et al:: Mechanisms of evolution in Rickettsia conorii and $\boldsymbol{R}$. prowazekii. Science 200I, 293:2093-2098.

24. Fournier PE, Raoult D: Identification of rickettsial isolates at the species level using multi-spacer typing. BMC Microbiol 2007, 7:72.

25. Ellison DW, Clark TR, Sturdevant DE, Virtaneva K, Porcella SF, Hackstadt T: Genomic comparison of virulent Rickettsia rickettsii Sheila Smith and avirulent Rickettsia rickettsii lowa. Infect immun 2008, 76:542-550.

26. McLeod MP, Qin X, Karpathy SE, Gioia J, Highlander SK, Fox GE, et al.: Complete genome sequence of Rickettsia typhi and comparison with sequences of other rickettsiae. J Bacteriol 2004, I 86:5842-5855.

27. Burgdorfer W, Ormsbee RA, Schmidt ML, Hoogstraal H: A search for the epidemic typhus agent in Ethiopian ticks. Bull WHO 1973, 48:563-569.

28. Ogata H, Renesto $P$, Audic S, Robert C, Blanc G, Fournier PE, et al: The genome sequence of Rickettsia felis identifies the first putative conjugative plasmid in an obligate intracellular parasite. PLOS Biol 2005, 3:e248.

29. Blanc G, Ogata H, Robert C, Audic S, Claverie JM, Raoult D: Lateral gene transfer between obligate intracellular bacteria: evidence from the Rickettsia massiliae genome. Genome Res 2007, I 7:1657-1664.

30. Cascales E, Christie PJ: The versatile bacterial type IV secretion systems. Nat Rev Microbiol 2003, I:I37-149.

31. Cho NH, Kim HR, Lee JH, Kim SY, Kim J, Cha S, et al.: The Orientia tsutsugamushi genome reveals massive proliferation of con- 
jugative type IV secretion system and host-cell interaction genes. Proc Natl Acad Sci USA 2007, 104:798I-7986.

32. Roux V, Raoult D: Phylogenetic analysis of the genus Rickettsia by I6S rDNA sequencing. Res Microbiol 1995, I46:385-396.

33. Fournier PE, Roux V, Raoult D: Phylogenetic analysis of spotted fever group rickettsiae by study of the outer surface protein rOmpA. Int J Syst Bacteriol 1998, 48:839-849.

34. Roux V, Raoult D: Phylogenetic analysis of members of the genus Rickettsia using the gene encoding the outer-membrane protein rOmpB (ompB). Int J Syst Evol Microbiol 2000, 50:1449-1455

35. Gillespie J], Williams K, Shukla M, Snyder EE, Nordberg EK, Cerau SM, et al.: Rickettsia phylogenomics: unwinding the intricacies of obligate intracellular life. PLOS ONE 2008, 3:e2018.

36. Williams KP, Sobral BW, Dickerman AW: A robust species tree for the alphaproteobacteria. J Bacteriol 2007, 189:4578-4586.

37. Baldridge GD, Burkhardt NY, Felsheim RF, Kurtti T], Munderloh UG Transposon insertion reveals pRM, a plasmid of Rickettsia monacensis. Appl Environ Microbiol 2007, 73:4984-4995.

38. Baldridge GD, Burkhardt NY, Felsheim RF, Kurtti TJ, Munderloh UG Plasmids of the pRM/pRF Family Occur in Diverse Rickettsia species. Appl Environ Microbiol 2008, 74:645-652.

39. Matsunaga T, Okamura Y, Fukuda Y, Wahyudi AT, Murase $Y$, Takeyama $\mathrm{H}$ : Complete genome sequence of the facultative anaerobic magnetotactic bacterium Magnetospirillum sp. strain AMB-I. DNA Res 2005, 12:157-166.

40. Burgdorfer W, Brinton LP: Mechanisms of transovarial infection of spotted fever Rickettsiae in ticks. Ann N Y Acad Sci 1975 , 266:6I-72.

4I. Cashel M, Gentry DR, Hernandez VJ: The stringent response. In Escherichia coli and Salmonella: Cellular and Molecular Biology Edited by: Neidhardt FC, Curtis III R, Ingraham JL, Lin ECC, Low KB, Magasanik B, et al. Washington, D.C.: ASM Press; 1996: |458-1496.

42. Rovery C, Renesto P, Crapoulet N, Matsumoto K, Parola P, Ogata H, et al:: Transcriptional response of Rickettsia conorii exposed to temperature variation and stress starvation. Res Microbiol 2005, 156:211-218.

43. La MV, François P, Rovery C, Robineau S, Barbry P, Schrenzel J, et al:: Development of a method for recovering rickettsial RNA from infected cells to analyze gene expression profiling of obligate intracellular bacteria. J Microbiol Meth 2007, 71:292-297.

44. Teysseire N, Raoult D: Comparison of Western immunoblotting and microimmunofluoresence for diagnosis of Mediterranean spotted fever. / Clin Microbiol 1992, 30:455-460.

45. Li H, Walker DH: RompA is a critical protein for the adhesion of Rickettsia rickettsii to host cells. Microbial Pathogenesis 1998 24:289-298.

46. Martinez JJ, Seveau S, Veiga E, Matsuyama S, Cossart P: Ku70, a component of DNA-dependent protein kinase, is a mammalian receptor for Rickettsia conorii. Cell 2005, I 23:1013-1023.

47. Blanc G, Ngwamidiba M, Ogata H, Fournier PE, Claverie JM, Raoult D: Molecular Evolution of Rickettsia Surface Antigens: Evidence of Positive Selection. Mol Biol Evol 2005, 22:2073-2083.

48. Walker TS, Winkler HH: Penetration of cultured mouse fibroblasts (L cells) by Rickettsia prowazeki. Infect Immun 1978, 22:200-208

49. Blanc G, Renesto P, Raoult D: Phylogenic analysis of rickettsial patatin-like protein with conserved phospholipase $\mathrm{A2}$ active sites. Ann N Y Acad Sci 2005, 1063:83-86.

50. Gouin E, Egile C, Dehoux P, Villiers V, Adams J, Gertler F, et al.: The RickA protein of Rickettsia conorii activates the Arp2/3 complex. Nature 2004, 427:457-46I.

5I. Christie PJ, Vogel JP: Bacterial type IV secretion: conjugation systems adapted to deliver effector molecules to host cells. Trends Microbiol 2000, 8:354-360.

52. Beati L, Kelly PJ, Matthewman LA, Mason PR, Raoult D: Prevalence of rickettsia-like organisms and spotted fever group rickettsiae in ticks (Acari: Ixodidae) from Zimbabwe. J Med Entomol 1995, 32:787-792.

53. Fournier PE, Zhu Y, Ogata $H$, Raoult D: Use of highly variable intergenic spacer sequences for multispacer typing of Rickettsia conorii strains. I Clin Microbiol 2004, 42:5757-5766.

54. Pallen MJ, Wren BW: Bacterial pathogenomics. Nature 2007, 449:835-842.
55. Fraser-Liggett CM: Insights on biology and evolution from microbial genome sequencing. Genome Res 2005, I5:1603-1610.

56. Raskin DM, Seshadri R, Pukatzki SU, Mekalanos Jj: Bacterial genomics and pathogen evolution. Cell 2006, |24:703-7|4.

57. Fuxelius HH, Darby AC, Cho NH, Andersson SG: Visualization of pseudogenes in intracellular bacteria reveals the different tracks to gene destruction. Genome Biol 2008, 9:R42.

58. Andersson SGE, Zomorodipour A, Andersson JO, Sicheritz-Pontén T, Alsmark UCM, Podowski RM, et al:: The genome sequence of Rickettsia prowazekii and the origin of mitochondria. Nature 1998, 396:133-140.

59. Walker $\mathrm{DH}, \mathrm{Yu} \mathrm{XJ}$ : Progress in rickettsial genome analysis from pioneering of Rickettsia prowazekii to the recent Rickettsia typhi. Ann N Y Acad Sci 2005, 1063:13-25.

60. Zhang D, Xu Z, Sun W, Karaolis KR: The Vibrio pathogenicity island-encoded Mop protein modulates the pathogenesis and reactogenicity of epidemic Vibrio cholerae. Infect immun 2003, 71:5I0-5I5.

6I. Federle MJ, Mclver KS, Scott JR: A response regulator that represses transcription of several virulence operons in the group A streptococcus. J Bacteriol 1999, I 8 I:3649-3657.

62. Glass Jl, ssad-Garcia N, Alperovich N, Yooseph S, Lewis MR, Maruf M, et al.: Essential genes of a minimal bacterium. Proc Natl Acad $\mathrm{Sci}$ USA 2006, 103:425-430.

63. Kaser M, Pluschke G: Differential Gene Repertoire in Mycobacterium ulcerans Identifies Candidate Genes for Patho-Adaptation. PLoS Negl Trop Dis 2008, 2:e353.

64. Kelly PJ, Mason PR: Transmission of a Spotted Fever Group Rickettsia by Amblyomma hebraeum (Acari: Ixodidae). J Med Entomol I99I, 28:598-600.

65. Burgdorfer W: Investigation of transovarial transmission of Rickettsia rickettsii in the wood tick Dermacentor andersoni. Exp Parasitol 1963, 14:152.

66. Niebylski ML, Peacock MG, Schwan TG: Lethal effect of Rickettsia rickettsii on its tick vector (Dermacentor andersoni). Appl Environ Microbiol 1999, 65:773-778.

67. Matsumoto K, Brouqui P, Raoult D, Parola P: Experimental infection models of ticks of the Rhipicephalus sanguineus group with Rickettsia conorii. Vector Borne Zoonotic Dis 2005, 5:363-372.

68. Lepidi H, Fournier PE, Raoult D: Histologic features and immunodetection of African tick-bite fever eschar. Emerg Infect Dis 2006, I 2:1332-1337.

69. Eremeeva ME, Klemt RM, Santucci-Domotor LA, Silverman DJ, Dasch GA: Genetic analysis of isolates of Rickettsia rickettsii that differ in virulence. Ann N Y Acad Sci 2003, 990:717-722.

70. Altschul SF, Madden TL, Schaffer AA, Zhang J, Zhang Z, Miller W, et al.: Gapped BLAST and PSI-BLAST: a new generation of protein database search programs. Nucleic Acids Res 1997 25:3389-3402.

7I. Bairoch A, Apweiler R, Wu CH, Barker WC, Boeckmann B, Ferro S, et al.: The Universal Protein Resource (UniProt). Nucleic Acids Res 2005, 33:DI54-DI59.

72. Marchler-Bauer A, Anderson JB, Cherukuri PF, Weese-Scott C, Geer LY, Gwadz M, et al: CDD: a Conserved Domain Database for protein classification. Nucleic Acids Res 2005, 33:D I92-DI 96.

73. Ponting CP, Schultz J, Milpetz F, Bork P: SMART: identification and annotation of domains from signalling and extracellular protein sequences. Nucleic Acids Res 1999, 27:229-232.

74. Lowe TM, Eddy SR: t-RNAscan-SE: a program for imroved detection of transfer RNA gene in genomic sequence. Nucleic Acids Res 1997, 25:955-964.

75. Eddy SR: Hidden Markov models. Curr Opin Struct Biol 1996 6:36I-365.

76. Thompson JD, Gibson TJ, Plewniak F, Jeanmougin F, Higgins DG: The CLUSTAL_X windows interface: flexible strategies for multiple sequence alignment aided by quality analysis tools. Nucleic Acids Res 1997, 25:4876-4882.

77. Notredame C, Higgins DG, Heringa J: T-Coffee: A novel method for fast and accurate multiple sequence alignment. J Mol Bio 2000, 302:205-217

78. Edgar RC: MUSCLE: a multiple sequence alignment method with reduced time and space complexity. BMC Bioinformatics 2004, 5: II3.

79. Katoh K, Misawa K, Kuma K, Miyata T: MAFFT: a novel method for rapid multiple sequence alignment based on fast Fourier transform. Nucleic Acids Res 2002, 30:3059-3066. 
80. Kumar S, Tamura K, Nei M: MEGA3: Integrated software for Molecular Evolutionary Genetics Analysis and sequence alignment. Brief Bioinform 2004, 5:150-163.

Publish with Bio Med Central and every scientist can read your work free of charge

"BioMed Central will be the most significant development for disseminating the results of biomedical research in our lifetime. " Sir Paul Nurse, Cancer Research UK

Your research papers will be:

- available free of charge to the entire biomedical community

- peer reviewed and published immediately upon acceptance

- cited in PubMed and archived on PubMed Central

- yours - you keep the copyright

Submit your manuscript here:

http://www.biomedcentral.com/info/publishing_adv.asp
BioMedcentral 